Published in Deakin, J., Taylor, E. and Kupchik, A. (2018The Palgrave Handbook of School Discipline: Surveillance, Punishment and Social Control. London: Palgrave Macmillan. Chapter 27. pp.529-552

\title{
Looking for strategic alternatives to school exclusion
}

\section{Carl Parsons}

School exclusions for disciplinary reasons happen on different scales, are managed in different ways, are underpinned by different mixes of care and punishment and signal different things about the nature of our societies. There is a greater exclusionary tendency in English schools compared with neighbours and those we would want to be compared with (Parsons, 2005).

This chapter, first, sets out the recent history of school disciplinary exclusions, mainly in the U.K., more specifically in England, before detailing a solution to the exclusion problem in the form of Community Based Inclusion. The first part of this chapter poses the problem of exclusion by examining the way it is applied; to whom, with what consequences and what values underlie this response to breeches of school discipline. The overarching statement representing the regulations governing the use of exclusions from state maintained schools (but not those in the private, fee-paying sector) states:

'Any decision of a school, including exclusion, must be made in line with the principles of administrative law, i.e. that it is: lawful (with respect to the legislation relating directly to exclusions and a school's wider legal duties, including the European Convention of Human Rights); rational; reasonable; fair; and proportionate' (DfE, 2012a. para 5).

A general concern about exclusion is that it removes the child from a key socializing experience, central to participating as a citizen. More worrying is the lack of oversight to which pupils are subject post-exclusion.

The second part of this chapter responds to the problem with a solution which is termed Community Based Inclusion. This relies on education providers and support services working speedily to prevent the exclusion by broadening a school's provision (units etc) or providing a place of education suited to the needs of a child who has been excluded, or is on the brink of exclusion or needs a period of therapeutic input. Managed moves to another school or alternative provision and the involvement of other professionals, whether in the original school or an alternative educational placement, are vital parts of a collective strategy.

\section{The English way to exclude children from school}


England manages exclusion differently from the other countries of the U.K. It also records higher rates of formal exclusion - called 'off-rolling' in Scotland and 'suspension/expulsion' in Northern Ireland (Riddell and McCluskey, 2013; Welsh Government, 2016; DENI 2016) ${ }^{1}$. England differs similarly from neighbouring European mainland countries, where many do not have regulations on how children can be removed from education but only on how education is to be assured for all. Contributions to Walraven et. al. (2000) describe differences across OECD countries in their understandings and management of 'at risk' children and young people. England has recently overhauled the regulations and the financing of exclusions (DfE, 2014b) where the key change is that schools retain the money previously held by the local authority (LA) and finance any alternative provision. This means that schools retain responsibility for their children, not the local authority, taking a portion of the funding and making provision. School inspectors are likely to be critical of high levels of exclusion - which can 'trigger an inspection' (Ofsted, 2014. p 4) - but seldom does this affect the overall judgment given on a school's quality.

The guide to the legislation governing school exclusions (DfE, 2012a) contains some statutory requirements, mostly legalistic and does not place emphasis on the protection and development of the excluded child. The guidance is essentially about 'administrative' matters: head teacher's responsibility to inform parents; governing body's duty to consider the exclusion and to reconsider a decision if a review panel so recommends. The 'Key points' section begins: 'Good discipline in schools is essential to ensure that all pupils can benefit from the opportunities provided by education. The government supports head teachers in using exclusion as a sanction where it is warranted. However, permanent exclusion should only be used as a last resort' (DfE, 2012a. p 4). Concerns are raised about 'unmet needs' and there is recognition of the higher rates of exclusion for special educational needs (SEN) pupils ${ }^{2}$, those eligible for free school meals (FSM) as well as those from Gypsy/Roma, Travellers of Irish Heritage and Black Caribbean communities (p 7).

The limit for fixed period exclusions is 45 days in any one school year. This actually amounts to a quarter of the school year! In 2014/15, secondary schools, where $80 \%$ of pupils are excluded, $15 \%$ of instances are for three or more days (DfE, 2016a. table 11) and $20 \%$ are excluded on three or more occasions (table 12). In the case of a permanent exclusion, the school or the local authority, must arrange for suitable 'appropriate fulltime education to begin no later than the sixth day of the exclusions'. Even officially tolerating this interruption of a child's education demeans the importance of education in the life of young people and is state neglect, very much the thrust of the Office of the 
Children's Commissioner reports (OCC, 2012, 2013). Education is not a privilege which might be lost through bad behaviour but both an individual right and a requirement by society for both personal and wider social participation and productivity reasons.

The newest guidance has given schools in England more rights in relation to exclusions, principally replacing the Independent Appeals Panel (IAP) by the Independent Review Panel (IRP) where the latter cannot overturn the exclusion decision but only require that it be reconsidered. Parents have reduced rights. Litigation is rare, yet some schools or academy chains and even parents have instructed barristers to represent their case and it is possible to refer on to the ombudsman or to judicial review. This has been argued as a wrong-headed to path to go down (Harris and Parsons, 2014) because again it deflects attention from unmet needs and questions of appropriate provision for the young person (White and Wyn, 2008).

Formally reported exclusions, permanent or fixed period, are no longer the main way in which a pupil is removed from the mainstream school setting. Increasingly regulated since 1986 in England, the system had been simple: a permanent exclusion resulted in a pupil being sent to a Pupil Referral Unit (PRUs) run by the LA. More recently, Alternative Provision (AP) has become the umbrella term for PRUs and other facilities set up by other voluntary or statutory groups or as AP Academies or AP Free Schools, though numbers in the schools census are still recorded separately for PRUs and AP. For those aged over 14 this placement was likely to be the permanent placement. For younger pupils there would be attempts at reintegration - the 'revolving door' facility.

Over the years there has been a growth of school inclusion units, often with a range of uplifting and non-stigmatising names (eg LIFE - Learning Is For Everyone) which schools have set up for themselves for young people whose behaviour cannot be managed in the mainstream classroom. This provision is not 'exclusion' and can be therapeutic, restorative and caring. Equally, it can be a dumping ground, for the benefit of the other pupils and with less designed provision for those it receives. Over the years, 'Behaviour Czars', Alan Steer, Charlie Taylor and Tom Bennett (DfES, 2005; DfE 2012, 2017), note the variety of in-school alternative provision, differing goals which span punishment to restoration and hint at the limited benefits of a narrow focus on bad behaviour; wider school culture needs attention too. Tom Bennett, in tacit acknowledgement of how internal inclusion units may fall short, cites cost as 'a major obstacle to designing more muscular units' (DfE, 2017. p. 45) which might support reintegration. 
Permanent exclusions were high in the mid-1990s at around 15,000 per year (Parsons, 2012. p. 4/5) but have been reduced to 5,000 (4,950 in 2013/14; 5,800 in 2014/15 - DfE, 2016a) since the early 2000s. This has moved the problem rather than solved it, and not only because of in-school provision for behaviourally challenging young people and managed moves but because of the exploitation of other means of effecting exclusion in an increasingly marketised environment freed from local authority oversight. Even the official numbers in PRUs and AP have, in the most recent figures available, shown significant increase as shown in Table 27.1 below.

Table 27.1: Numbers in Pupil Referral Units and in Alternative Provision 2014 - 16

\begin{tabular}{lll}
\hline $\begin{array}{l}\text { Year of } \\
\text { January census }\end{array}$ & $\begin{array}{l}\text { Total pupils in } \\
\text { Referral Units }\end{array}$ & $\begin{array}{l}\text { Total pupils in local authority } \\
\text { alternative provision }\end{array}$ \\
\hline $\mathbf{2 0 1 4}$ & 12,895 & 20,215 \\
$\mathbf{2 0 1 5}$ & 13,583 & 20,503 \\
$\mathbf{2 0 1 6}$ & 15,015 & 22,032 \\
\hline
\end{tabular}

Source: DfE, 2014a, 2015, 2016c Table 1b in each case

The new 'front line' in exclusions in 2016 and beyond comprises PRUs and Alternative Provision $(\mathrm{AP})^{3}$, 'transfers' and more dubious informal ways of effecting that removal. The diverse ways of removing 'unwanted pupils' that we can count are:

1. Permanent exclusions have reduced to around 5,000, 66\% with some level of SEN (2013/14). Most go to PRUs and AP (DfE, 2016a).

2. Fixed Term Exclusions (FTEs) numbered 143,000 instances, 10\% with statements and 43\% with SEN without statements (DfE, 2016a) ${ }^{4}$.

3. Pupil Referral Units (PRUs) accommodate 15,000 pupils and 22,000 are in Alternative Provision (AP); half are in Year 11. Most are on managed moves, dual registration or short-term placement. The January 2016 census reported that $77 \%$ of pupils in PRUs had SEN of some description (DfE, 2016, Table S1).

4. Elective Home Education (EHE) is the formally recorded education for $27,000^{5}$ children as recorded in July 2014 (DfE, 2016b, p. 119), an increase of 65\% over six years. An estimate of those 'pushed' into this option is 9,000. Parents can be 'encouraged' to take this option by increased numbers of FTEs and suggestions from the school that they look for alternatives (BBC, 2015).

There are further means of removing a child from a school where we can only estimate from informed professionals' sources. The figures below are not available from the official statistics regularly collected and published by the Department for Education. They are important, worrying and possibly frequent means of quasi-exclusion. They result in a child not getting what one would regard as a proper education.

5. Reduced timetables, sometimes for medical reasons but reportedly used for some at risk of exclusions but it is recommended that it is short-term. Pupils may be in school for a few hours per day. Estimated numbers are 30,000 for at risk of exclusion pupils $(2014 / 15)$. Ofsted's ${ }^{6}$ (2013) enquiry of a sample of LAs estimates 
10,000 (p. 7) across England but the time period is unclear and almost certainly a big underestimate.

6. Extended study leave, usually year 11 (the GCSE examination year) where pupils are off the school site, ostensibly to prepare for exams; reports suggest its wider use. Estimated numbers 20,000 (2014/15).

7. Attendance code B - Approved off-site educational activity is a frequently cited location for some challenging pupils. This can be work experience or a form of AP for part of their timetable, but it is difficult to differentiate those at risk of exclusion and pupils on courses shared with another school. Incidental reports, aggregated up give us an estimate of 15,000 young people where this is a form of exclusion.

8. Children Missing Education (CME). This is a worrying child protection area extending from long-term truants with limited efforts to get them into school to children completely off the radar or have run away from home or care. It happens usually when a pupil is removed from the school, usually by the parent, and no replacement school is identified, evident when no new school requests the pupil's file (DfE, 2016b). All local authorities have guidance on this (DfE, 2015b) but a child removed from a school's register is not necessarily reported to the local authority. Numbers have been estimated at 12,000, but it should be noted that one third of LAs reported 'none', which is difficult to believe (Collins, 2011).

Though the official permanent exclusion statistics have shown a great reduction, there are still as many troubled and challenging young people in our school system. Omitting fixed period exclusions, and accepting some estimating, we know of 56,000 school age children designated as needing to be educated outside mainstream education (1, 3 and 4 above) not including the special school population. More speculatively, an additional 77,000 are part of an unrecorded population outside mainstream in much less supervised circumstances (4 -8 above). In total it amounts to approximately $1.7 \%$ of the total school population. (DfE, 2015a)

Of those excluded, most are boys with an overall gender ratio of $3: 1,80 \%$ are from secondary schools with a peak at year 10 (aged 15) and unchanging inequalities are stark, as discussed in the next section. In 2013/14, only $1.2 \%$ of pupils in alternative provision and Pupil Referral Units achieved 5 or more A*- C grade GCSE passes, or equivalent, including English and mathematics; the national average was 53\% (DfE, 2015c, Table $\mathrm{P} 1)$.

\section{State duties and professional responsibilities}

The permanent and fixed term exclusion of young people from school, through a specific education law, is peculiarly British if not English. The removal of education, even for a short period, unless for the health and safety of the child or the wider school community, 
is individually and socially damaging (OCC, 2013). An education system should be designed to meet the needs of ALL pupils and, while this might not be in mainstream school, it should provide locations and personnel to ensure that appropriate education is available to even the most challenging young people. The outcomes for permanently excluded young people are, in general, poor, as stated above, and it is vital to find other ways of managing the continued education and development of these young people.

Exclusions are a punitive response to troubled young people, operating as part of discipline policies and seldom serving to change, support and develop the dependent young. Furthermore, the quality of Alternative Provision (AP) to which they are referred as a substitute for exclusion has been criticised and is known to be 'variable', often unregistered, not offering full-time education and giving access to only low level qualifications (Ofsted, 2016).

Exclusion as a method of upholding discipline is not generally seen as a way of improving the behaviour, social skills, learning or life chances of the young person excluded (Munn et. al. 2000; Parsons, 1999). Fixed period exclusions, usually for only one or two days, are a peculiar device which interrupts the child's education, often an education that is not going too well, and acts to devalue the very idea of education. We want ALL our pupils attending school or a suitable full-time place of worthwhile and appropriate education. Permanent exclusions are punitive, show the displeasure of the supervising adults and the institution and are an expression of anger and rejection, exactly replicating the behaviour of the pupils at risk of exclusion.

INAURA, the inclusion charity (INAURA, 2008), once advocated that school exclusions should be made illegal; since 2009, the mantra has been, 'School exclusions are redundant!' Hearteningly, the current statistics (DfE, 2016a) show that out of England's 152 local authorities, 10 record zero or fewer than five permanent exclusions and 23 exclude at under half the average national rate of $0.7 \%$. For some LAs, this is a genuine commitment to inclusion managed in a variety of non-punitive ways; for others there is resort to the more covert ways described earlier, of removing a child from the school. Fixed period exclusions, running at nearly a third of a million instances annually, averaging 2.3 days each, mean that over 700,000 school days are lost. There has to be a better way to manage disaffection. INAURA's notion of Community Based Inclusion is the way forward where schools and other education providers form a network of provision 
and pupils can be moved within a quality assured, supportive community, designed to cater for the full range of social and educational needs.

The state could legislate or publish directives which set out what was expected for children that a school claimed it could not work with. Ofsted or a body with similar oversight needs to see that there is compliance and apply sanctions where there is disregard of guidance. Ideally, head teachers and teacher unions should express clearly their position as educators and shapers of the future citizenry and expound their expectations for inclusion in the greater, multi-layered, educational community. The moral case on these two levels is, at least for some, compelling.

\section{Social justice and equality}

Missing mainstream education disproportionately affects children experiencing other disadvantages and unmet needs, whether poverty or special needs. Gender and ethnicity are further factors associated with differing rates of exclusion. Table 27.2 sets out the variations. In terms of social justice and equality, the picture is quite shocking. Pupils with special needs are around ten times more likely to be permanently excluded and four times more likely to receive a fixed period exclusion. Pupils eligible for free school meals (FSM) are four times as likely to be excluded permanently or for a fixed period. In terms of ethnicity, Gypsy/Roma and Irish Travellers top the rates of exclusion, experiencing permanent exclusion at over five times the average rate and fixed period exclusions at four times the national average rate. Those identified as Black Caribbean and Mixed White and Black Caribbean continue to be permanently excluded at three times the rate of white children and excluded for a fixed term at twice the rate. The picture changes little when other factors, most notably FSM-status, are taken into account (Parsons et al. 2009, 2016). Some writers claim it is racism, deeply embedded within institutional practices and policies (Gillborn, 2008), and it is clear that the education stipulated by the state suits some groups more than others, raising questions about the extent to which the education system is responsive to need and professionals are motivated and equipped to shape an educational experience that is more inclusive. It is interesting to note that Asian pupils are excluded at lower rates, as are Black African pupils, and boys are excluded at three times the rate of girls. Children experiencing poverty, whether signified by Free School Meals entitlement or living in the poorest IDACI (Income Deprivation Affecting Children Index) areas, have significantly higher rates of exclusion than the mean. It is notable that, in attainment terms at every level of national testing, from the Foundation Stage Profile to $\mathrm{KS} 4$, this inequality is apparent. 
Table 27.2: School exclusions by ethnicity 2014/15

\begin{tabular}{lll}
\hline & \multicolumn{2}{c}{ \% of the ethnic group } \\
\cline { 2 - 3 } & PERMANENT & FIXED PERIOD \\
\hline Mixed White British & 0.09 & 4.67 \\
Irish & 0.10 & 4.65 \\
Traveller of Irish heritage & 0.47 & 17.49 \\
Gypsy/ Roma & 0.48 & 18.58 \\
Any other White background & 0.06 & 2.85 \\
\hline Mixed White and Black Caribbean & 0.22 & 8.86 \\
Mixed White and Black African & 0.08 & 5.14 \\
Mixed White and Asian & 0.06 & 3.18 \\
Other Mixed background & 0.11 & 4.43 \\
\hline Indian & 0.01 & 0.80 \\
Pakistani & 0.05 & 2.77 \\
Bangladeshi & 0.03 & 1.83 \\
Other Asian background & 0.03 & 1.35 \\
\hline Black Caribbean & 0.28 & 9.64 \\
Black African & 0.07 & 3.84 \\
Other Black background & 0.11 & 5.76 \\
Chinese & $\mathbf{x}$ & 0.47 \\
\hline Boys & 0.13 & 6.33 \\
Girls & 0.04 & 2.38 \\
\hline Free school meals & 0.22 & 10.11 \\
Non-free school meals & 0.05 & 2.77 \\
Poorest 10\% & 0.11 & 5.36 \\
Most affluent 10\% & 0.05 & 2.67 \\
All pupils & $\mathbf{0 . 0 7}$ & $\mathbf{3 . 9 6}$ \\
Overall numbers & $\mathbf{5 7 7 0}$ & $\mathbf{3 0 0 , 6 3 0}$ \\
\hline Source: DF 2016a, National & 9.300 \\
\hline
\end{tabular}

Source: DfE 2016a, National_tables SFR26/2016, Tables 8, 9 and 10

The astonishing fact is that these perverse inequalities for special needs, poverty, and race have persisted for approaching 20 years, since statistics of this kind were first available. This is not new. It is, as the Children's Commissioner has said, a source of shame (OCC, 2012).

Good practice in relation to inclusion for assessed special educational needs and disabilities or for discipline would mean that a school, or the community of education providers, have in place appropriate provision for all children. They would also have professionals or agents who can mediate and ease any transition, advising parents and schools about options and agreeing the child's placement. In Strategic Alternatives to Exclusion from School (Parsons, 2011a), evidence is given of how schools in a local area can collectively design their provision so that all children are catered for: community based inclusion. 
This involves 'broadening the school' by setting up units and centres within the school for those who are deemed to struggle in the mainstream classroom; 'building the bridges' so that managed moves can be organised to another school or location for education; and 'alternative provision' to which children might be referred for a mix of educational experience better suited to their attributes. All of this needs to be of suitable quality and there are enough examples of this done well (case studies in Parsons, 2011a; Arnold et.al., 2009) to demonstrate the feasibility of inclusion practice which put a child's well-being at the centre. Conversely, there are poor Pupil Referral Units, such as those referred to by DfE, (2012) where:

'children rarely get back to mainstream ... curriculum is narrow ... teaching poor and pupils do not achieve academic success. Rather than improving behaviour, the atmosphere of the worst PRUs feeds their pupils' behaviour problems. Some of the most vulnerable children, with a range of differing needs, end up in bleak one-sizefits- all provision.' (p. 19)

Anecdotes abound about academies excluding by the backdoor, using 'the dark arts' of subtly but strongly suggesting a move for the young person might be best (BBC, 2012), offering inaccessible alternative provision as the option to pupils excluded (fixed term or permanent), placing barriers to the admission of special needs pupils, registering pupils as attendance code B (approved off-site educational activity) when they have been required not to attend and not following up with any vigour pupils who do not attend and, in effect, are CME.

\section{The solution: Community Based Inclusion}

Community Based Inclusion (INAURA, 2008) is about the design and management of aggregate educational provision in an area such that there is recognition of the full range of needs and commitment and practical action to meet these needs. As the English education system fragments with local authority schools reducing in number and academies and free schools on the increase, organising across an area becomes more difficult though it is still encouraged and is evident even amongst groupings that include Local Authority (LA) schools and academies (Parsons, 2011b).

Schools are the big players with some secondary schools looming over the neighbourhood like aircraft carriers in the harbour with an influence on a locality extending beyond academic learning. Some head teachers have budgets of over $£ 10$ million. They have the resources to spend flexibly and allocate disproportionately to meet needs, including where there is a perceived challenge to school discipline with no diagnosed special need. 
It is how an LA or academy chain and its schools, clusters of schools or children's trusts work this through that is crucial, and front line education officers doing business with their schools is central to working out satisfactory arrangements that will endure. Local and individual action is fundamentally motivated by understanding where a strategy fits and the broad range of reasons for it. Head teachers, teachers and other agents need to see the social purpose of education, the moral purpose of social care and the unequal impact of actions like exclusion on particular groups in society. They need to see also the longer term damage and the costs to society of allowing the emergence of young people who are illequipped to work, relate to others or manage themselves.

The shared commitment across schools and LA members and officers with explicit principles and procedures is a foundation to the school inclusion effort. Local political support and agreed principles and protocols with schools need to be established: key principles include protocols and mechanisms for the allocation of hard to place pupils. A number of objective scoring schemes, sometimes with finance attached, are available and can be negotiated to work with groups of head teachers; Suffolk, Havering and Rochdale are examples ${ }^{7}$.

Schools require speedy advice and action from LA Officers at times of crisis over a pupil's behaviour. Where this is provided, confidence increases and exclusions are minimised (Parsons, 2011a, p 54). There was a feeling that if schools in an area, comprising a partnership or cluster, were to accept shared ownership of all children in their area this would be an underlying principle which would enable transfers and more caring movement of pupils to be arranged (Abdelnoor, 2007).

Where a body of opinion can be established amongst head teachers about the proper way to proceed, fair sharing of difficult pupils and the procedures to be followed, colleagues can be brought into line by pressure from fellow head teachers (Parsons, 2011a, p. 61). School Improvement Partners and, increasingly in 2017 and beyond as LAs diminish, freelance consultants available to the school are an important resource which is probably under-utilised at present. Multi Academy Trusts (MATs) and Academy chains may have their own resources and sharing of practice to avoid exclusions. There needs to be inputs at both strategic and classroom practice levels to develop and sustain thinking and practice to equip schools to manage challenging children. This can vary from INSET sessions through to coaching for appropriate 
Working at 'hearts and minds' to gain support for including all children and responding to all needs may be an initial moral stimulus to set in place explicit inclusion principles and procedures. The intellectual and moral commitment is an important ingredient but insufficient alone. Pragmatics strongly suggest that if you can make it work first, then practical support and buy-in occur and the appropriate values emerge to reinforce developing successful practice. This is a key underlying finding from the Strategic Alternatives (Parsons, 2011a) work and pivotal has been a unifying, community, committed approach to all our children in our area. Head teachers will say they do not want to exclude and talk about the last resort; different head teachers have different thresholds for what counts as last resort. Showing it can work allows the moral power to connect with the practical and strategic drive to continue the education of all those who make up their school population.

The Strategic Alternatives project (Parsons, 2011a) extended earlier work (Abdelnoor, 1999; Parsons, 1999), confirming generic solutions to the exclusion challenge:

1. diverse and multi-level provision in schools - broaden the school

2. managed moves and school cluster responsibilities - build the bridges

3. alternative provision - find or make a place for every child

4. multiagency working - joining up the dots

\section{More diverse and multi-level provision in schools - broaden the school}

Head teachers are the legal agents making decisions on school exclusions. It is important to determine how far alterations in values and practices at school level might alter exclusion habits. While it is acknowledged that there is a 'hearts and minds' job to be done with schools by the local authority, there is also the need to encourage schools to set up their own layers of provision (inclusion units, etc.), entertain managed moves and engage in more creative thinking about alternative curriculum. One contributor noted that 'it can be disaffection from a poor curriculum that causes the problem' (Parsons 2011a, pp.114-5) and that improved curriculum has to go hand in hand with work with pupils and parents.

A flexibility of provision needs to be created and supported by schools and the Local Authority. This includes the use of social deprivation or Pupil Premium money in schools to set up units, employ learning mentors, fund alternative provision, etc., and the movement into and out of alternative provision and Pupil Referral Units needs to be kept fluid. There is a caring, developmental and supportive role for schools and LA personnel, 
particularly with children whose preparation for school or family support circumstances for school are limited and often at the root of their difficulties at surviving in school. While nurture groups are more often found in infant schools to prepare reception children, some secondary schools have actually developed classes which serve this function at their level.

Finance received by schools, portions of which are allocated for social deprivation, may not be appropriately used. One can raise questions about the extent to which schools spend their social deprivation and Pupil Premium money on those children. Examples of schools are described in earlier pages where a complex array of additional facilities are provided and a more varied workforce employed to better meet the needs of challenging young people. Local Authority $\mathrm{C}$ has been a long-term low excluder and its array of provision, 14 items are listed (Parsons, 2011a, p 26), is impressive. The warning is significant as education funding is 'variable' and in $2007 / 08$ ' $\ldots$ the LA is overspent on alternative provision!' (p. 21).

There is an ongoing need to give teachers confidence in themselves to develop relational skills to work with young people with challenging behaviour. In initial teacher education and continuing professional development, too great an emphasis is placed on behaviour policies and discipline policies, both of which place the problem with the young person. Relationship policies would suggest a shared responsibility! Some work would suggest a fundamental need on the part of school staff for respect for young people, 'playing the long game' and recognising the young people as decision-makers in their educational lives (Mann, 2017).

It is also necessary to overcome the divide that currently is manifest in the minds of education managers between the deserving special educational needs pupils and the undeserving EBD (emotional and behavioural difficulties) pupil. The Strategic Alternatives conclusion asserts that 'the righteousness that has often accompanied the whole business of exclusion [was] couched in terms of deservingness and necessity of the ejection, rejection and worthlessness of the child and the family' (p. 128); overriding this stance involves the school and its associated services taking the responsibility to meet the full range of needs evident in its school community.

\section{Managed moves and school cluster responsibilities - build the bridges}

As Abdelnoor (2007) argues, a managed move is more than the simple transfer of a pupil from one school to another but can be seen as an organised consensual movement of the 
pupil from school to school. This may be from school to alternative provision, or to the PRU or some other monitored and regulated provision. An important element in it is the emphasis on meeting need and a great diminution in the exercise of punishment.

It was emphasised that there should be a risk assessment before a managed move. It was evident that the full implementation of 'community based inclusion' had some way to go in the practice in most LAs and MATs with parent consultation, review, establishing induction and support arrangements in the receiving school and management of any breakdown not in place as routine.

It is not yet clear that subgroups of schools in LAs are generally ready to operationalise a managed transfer system unaided. The history of cooperative working, especially over 'difficult pupils' is not firmly in place. It can be developed (Parsons, 2011b).

\section{Alternative provision - find or make a place for every child}

There was considerable debate about what would count as satisfactory alternative provision, how it would be monitored and quality assured, and how attendance would be ensured (Ofsted, 2016). Some low excluding LAs have developed a range of alternative provision for children who are out of school and children who can no longer be managed in school. These children would ordinarily be excluded but are allocated to these facilities. It shows a farm experience which pupils receive for one day per week with other tailored curriculum provision in school for the other four days. There are reports from teachers, pupils, parents about alternative curriculum providers and all gave evidence about the value of the right mix of which the alternative provision could be part (Parsons, 2011b, pp. 28, 29). Consideration might be given to the 'waking hour's curriculum', and notschool.net (described as an online Summerhill). Some schools have a TIF (temporary inclusive facility), which is schooling from $3-6 \mathrm{pm}$.

There are challenges in funding, quality assuring and ensuring attendance at the alternative provision (Ofsted, 2016, p. 50; Parsons, 2011b, pp. 47, 57, 66). In one low excluding LA, there is a stated expectation of high attendance (they achieve $80 \%$ attendance) and a certificated outcome. If the alternative provider does not satisfy these requirements then referrals to them would be discontinued. There were also differences between attendees about what counted as full-time provision with some believing 18 hours a week would be officially acceptable and others reporting that a Joint Area Review required $23-25$ hours a week. 
At present, alternatives which can be provided for Key Stage 3 (aged 11 - 14) pupils are more limited than those available at Key Stage 4; where these are extended, it helps to reduce exclusions. There needs to be a creative approach to alternative provision and a reconsideration of what count as educational and developmental experiences, especially for children who find being at, and behaving in school, quite difficult. There are grounds for stretching the bounds of what would count as appropriate provision that keeps the child in touch with education and in a position to progress.

As Thomson and Russell (2007) showed in their mapping of alternative provision, there is work to be done in regularising the loose array of provision. There are signs that, where it is taken seriously, it can work with parent consultation, accreditation routes, monitoring and some transition to different forms of provision. At best, it is managed through schools with the other parts provided in-house, even if separately organised, in order to ensure a balance and basic skills acquisition.

\section{Multiagency working - joining up the dots.}

This means engaging with the full range of children's services including the voluntary sector. With Every Child Matters, Children's Services Directorates and Local Children's Services Partnerships the expectations of and opportunities for joined-up working are great. The ability to call on or arrange speedy referral to other professionals is developing. Some schools are discarding the notion of 'referral', as it passes the problem on, but regard working with other professionals as a collaboration for the benefit of the child where the school retains the responsibility. The extended school, the full service school and the community school all carry the overlapping expectation that the school stretches its remit and that teachers see themselves as part of a multiagency team. Stead et. al. (2004) report on 'dilemmas and tensions' (p. 42) and Huddart (2007), in the context of mental health work in schools, refers to 'joined on rather than joined up' (p. 421), but both point to in the direction of greater collaboration and cross-working with professionals in schools and elsewhere.

Schools need access to high quality intervention and prevention work (Arnold et. al., 2009; DfE, 2011; OCC, 2012). While there is a problem with outsiders coming in to solve problems with young people there have been many instances of well-respected external consultants working with groups, with teachers and with individuals modelling the ways to work best with pupils. Other schemes involving staff training or the application of particular methods with groups have reaped benefits. These include nurture groups, 
counselling and mentoring, self-esteem raising, family link work, youth work engagement to name few (Mann, 2017). It was said by a head teacher that, in respect of external support, 'money talks and size matters' (Parsons, 2011a, p. 117); the allocation of funding and the size of teams to offer support make a difference to schools' responses to challenging behaviour from children in their schools.

Multiagency working needs to be a reality and not an aspiration. Too often the principles of multiagency working are set and agreements made at a strategic level, but the aspiration is insufficiently driven through to practical implementation. The creation of small teams working in a case work manner has much promise. Locality based teams with defined case loads regularly monitored and assessed hold much promise; at best, these are integrated into the working of schools and teachers see themselves as part of a multiagency team.

The implementation of Children's Trusts should provide a locality based focus and hub for much of the supportive work needed to help youngsters who present behavioural challenges. During the Strategic Alternatives project, pupils and parents were interviewed, some of whom revealed considerable insights into their own situations. They are partners in the process and not simply the problem(s). Conflict resolution is needed in a number of areas to reconcile parties to work productively together; this can include overcoming difficulties between education and children's social care as well as between teachers and parents.

Even in an increasingly disaggregated system, there needs to be commitment to collective organisation for at risk young people $-a h u b$. Whether it is the Local Authority, Multi Academy Trust (MAT) or other formalised arrangement, for community based inclusion to work there has to be the organisational facility that designs, maintains and manages the collective system that is to cater for the educational needs of ALL pupils in the area. This may have at its core the Fair Access, Admissions and Resources Group (there are many different names) meeting regularly and dispensing business quickly. It should be attended by senior school representatives, mediating professionals who may need to ease transitions or assess further the suitability or readiness of a pupil for a particular setting. It may involve voting on decisions by those present! It may have control of resources to support a pupil, either in his/her current location or in another. The Fair Access Group should certainly be the forum for ascertaining what services should be commissioned and monitor transparently what is happening, who moves where and from where. Figure 27.1 illustrates an inclusive arrangement where the boundary is around a group of schools and other 
agents operating in the field of child care and education. This is also the boundary for finance, and the central hub is the vital operational heart of the system.

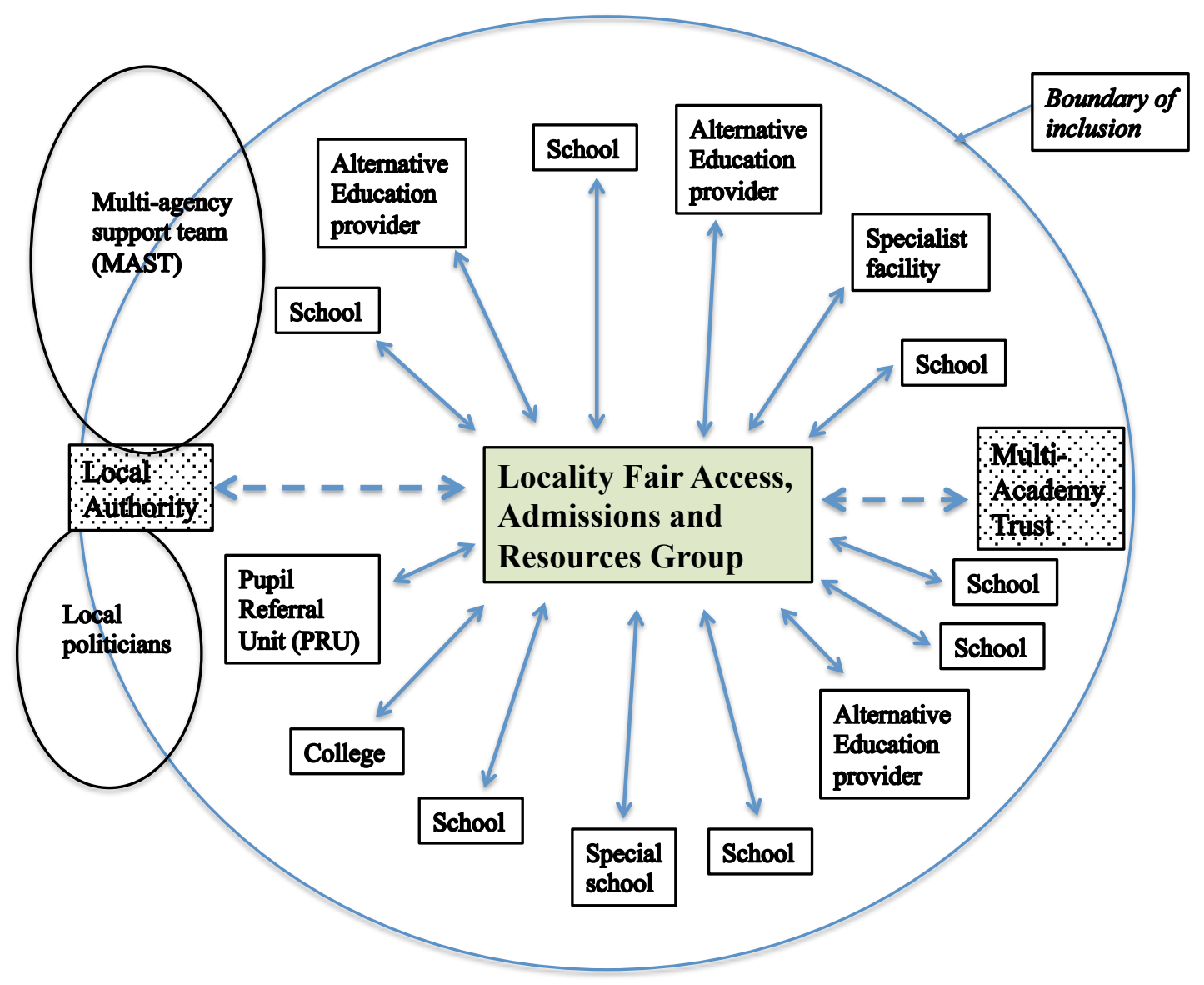

Figure 27.1: Schools, education providers operating through a Fair Access Group

The main groups which need to commit to such an arrangement are the school clusters or academy chains, associated Children's Trusts and local authorities. The articulation of complementary policies and practice across these collectivities should ensure that the education and care of behaviourally challenging children is better managed. This means caring, but hard-nosed decisions about the needs of the child, deflecting the punishment motive and, at inevitably increased short-term costs providing a quality education for the child - whether supported in (some of) the classrooms, allocated to a unit in the school, in an off-site unit, a mix of alternative provision and mainstream curriculum or a special school. The ultimate goal is a provision which meets the needs of the child with a sensible appreciation of what a mainstream school can cope with.

Parents, carers and young people deserve to be heard, to have their needs considered, to be treated fairly and to have the best interests of the young people at the centre of discussions 
and decisions. The state education system should be designed to address the needs and challenges presented by every learner and professional people should be trained and paid as public servants. Most young people who are challenging at school are challenging at home and the best way forward is an alliance between home and school which seeks the best way forward, one which does not entail legal representation and appeals.

Within schools, more attention needs to be given to support for behaviourally challenging young people, with better developed in-school arrangements for therapeutic work, isolation and restoration. This needs to be matched by routine ways of managing transfers in a conciliatory and participative way and for the use of alternative provision. Schools will need to adjust funding and allocate resources disproportionately to this small number of young people. Most will have funds for this, allocated in various ways by a formula which acknowledges the social deprivation of the school's intake; most notably, the Pupil Premium can add significantly to a school's budget ${ }^{8}$.

They will need to really establish cooperative protocols in which all (secondary) schools participate. Collectively, they will need to build an acceptance that all the children belong to this community and if they do have to move, then schools work to ensure this is supported and if the prospect of a return is kept open, the school maintains contact. School cluster or local delivery partnership arrangements are not firmly established and, if managed within themselves (ie not having a coordinating agent), one would doubt that progress would be quick and assured in the area of school exclusions.

There is a need for mediating staff who can 'do business' with head teachers to be present in schools and available to schools, people who can support schools in extending their provision and efforts for inclusion and have a sufficient voice at County/Town Hall or in academy chains to elicit more resources when this is necessary. Elsewhere, it has been suggested, not exactly tongue in cheek, that there is a need for an 'interagency czar' operating in a 'Stalinist environment' (Parsons and Hailes, 2004) with political backing and regularly monitored street level work.

Day 6 provision is an arrangement whereby, for the first five days following and exclusion, the school must (?) continue providing the educational material for a child who is at home; This has proved to be problematic and unhelpful in continuing the education for a pupil permanently excluded or on a longer term fixed-term exclusion. It awaits the replacement provision. The punitive tendency inherent in these policies (Parsons, 2005) regrettably runs 
counter to a position which is about meeting unmet needs, restorative approaches and preventative arrangements in schools and local authorities.

\section{Five barriers to minimising exclusion}

To conclude on a negative but realistic note in England's increasingly splintered schooling arrangements, there are a number of recurrent problems in school clusters adopting collective inclusionary practices.

1. The will to punish (Parsons, 2005) is about 'deservingness' which pervades the education field; young people who will not, or cannot, conform to the behavioural requirements set by school are considered in some sense 'undeserving' and to have disqualified themselves from education.

2. Difficulty of collaboration between schools and other providers (Stead et. al. 2004) and poor integration, cooperation and exchange amongst social/welfare services generally. Funding is part of the problem and in times of austerity there will be cuts to roles and functions regarded as beyond core work.

3. Absence of backing all the way up the line to senior education administrators and local politician level so that workers are supported in brokering, mediating and applying restorative approaches to inclusion.

4. The head teacher or principal who will not 'play ball' undermines community-wide commitment that exclusions be dealt with collectively. It is made difficult if some head teachers exclude excessively, play little or no role in managed moves or in organising their own alternative provision. Head teachers are varied in their stance on exclusions and can change to being more or less inclusive. In the Strategic Alternatives work Parsons, 2011a), the variations in school exclusion were attributed in LA 1 to 'leadership and management eg the philosophy of heads towards exclusions' (p. 41) and 'Different heads have different "ends of the road"” (p. 45).

5. The one-off incident accounts for about one third of permanent exclusion ${ }^{9}$. This is the event which the school judges needs a severe and public response. The offence might be violence or drugs. Both of these can be seen as strong invitations for preventative engagement with the young person to avoid future transgressions. The Strategic Alternatives work gave rise to many instances where for both the schools and behaviour services the offending behaviour and pupil were unexpected but seen as requiring instant and severe response.

\section{Concluding thoughts}


Permanent exclusion is a punishment and is damaging. It is a formal rejection of the child and is not designed to address the child's needs (Arnold et. al., 2009; White and Wyn, 2008). It is a casting off of the responsibility of mainstream schools collectively to manage the continued education of all their pupils. Fixed term exclusions, except for medical reasons, sometimes associated with mental health and anger-management issues, are also damaging, often putting children further behind in school work, learning and social acceptance. The use of short, and sometimes unreported, fixed term exclusions for 'cooling-off' after a heated incident or a tantrum are not encouraged but may be necessary for safety reasons. But they should not compromise the excluded pupil's safety. If further evidence were needed of damage to children then one need go no further than Arnold, et al (2009) for graphic accounts of the experience of exclusion for children and families.

A permanent exclusion is a process which has no forward plan. There is frequently a hiatus and loss of education and direction for the child after an exclusion (Abdelnoor, 2007. p 13). A transfer, respite or a managed move that is acceptably carried out always includes a forward plan and is distinctly different in character from an exclusion.

If the Every Child Matters, No Child Left Behind, Children's Rights mantra are not sufficiently powerful, then the financial imperative might be. Firstly, there is the bald fact that a pupil referral unit (PRU), alternative provisions (AP) place and other substitute education costs around three times the amount for a school place (Parsons, 2011a, p. 74) and PRU attainment outcomes are poor; $1.2 \%$ of pupils gained $5+\mathrm{A}_{-}{ }_{-} \mathrm{C}$ GCSEs including English and mathematics compared with a national average of $53.4 \%{ }^{10}$. Secondly, the marginalisation of these young people often brings with it other calculable expense as other services are called upon. Thirdly, there are the longer term costs about which we can only speculate, but these include, crime, mental health, unemployment, unemployability and struggling relationships and parenting. Education and child social care services can do much to reduce the likelihood of adverse consequences, whether for moral or financial motivations.

The barriers can be overcome, every child does matter, no child need be left behind and we can protect children's rights to being included in education of a kind that is accepting of and nurturing for them. It requires the community of education providers to collaborate in identifying a place for every child, speedily and with support, and maintaining the child in education, however challenging or negative their attributes. This is Community Based Inclusion. It is happening in some areas of the country and one can remain optimistic that 
best practices can be sustained and spread. The ultimate goal is education, care and development and the institutions involved and the discipline imposed must be to those ends.

\section{References}

Abdelnoor, Adam. 1999. Preventing Exclusions, Oxford: Heinemann.

Abdelnoor, Adam. 2007. Managed moves: A complete guide to managed moves as an alternative to permanent exclusion. London: Calouste Gulbenkian Foundation https://gulbenkian.pt/uk-branch/wp-content/uploads/sites/18/2007/01/Managedmoves-04-08.pdf

Arnold, Christopher, Jane Yeomans, Sarah Simpson and Mike Solomon. 2009. Excluded from school: complex discourses and psychological perspectives. Stoke on Trent: Trentham Books.

BBC News 2012. Academies accused of pushing difficult students out, London: BBC. http://news.bbc.co.uk/1/hi/programmes/newsnight/9674889.stm

BBC News 2015. Rising numbers of pupils home educated. London: BBC. http://www.bbc.co.uk/news/education-35133119

Collins, Nick. 2011. 12,000 children 'missing' from education. Telegraph, 11.02.2011 http:/www.telegraph.co.uk/education/8316118/12000-children-missing-fromeducation.html

DENI. 2016. Suspension and Expulsion Management Information 2015/16. Belfast: Department for Education Northern Ireland https://www.education-ni.gov.uk/publications/suspension-and-expulsionmanagement-information-201516

DfES. 2005. Learning Behaviour The Report of the Practitioners' Group on School Behaviour and Discipline. London Department for Educational and Skills. http://www.educationengland.org.uk/documents/pdfs/2005-steer-report-learningbehaviour.pdf

DfE. 2011. Getting the simple things right: Charlie Taylor's behaviour checklists. London: Department of Education. https://www.gov.uk/government/uploads/system/uploads/attachment_data/file/57164 0/Getting the simple things_right_Charlie_Taylor_s_behaviour_checklists.pdf

DfE. 2012a. Exclusion from maintained schools, Academies and pupil referral units in England: A guide for those with legal responsibilities in relation to exclusion. London: Department of Education. https://www.gov.uk/government/uploads/system/uploads/attachment_data/file/26968 1/Exclusion from maintained schools academies and pupil referral units.pdf

DfE. 2012b. Improving Alternative Provision. London: Department of Education. https://www.gov.uk/government/uploads/system/uploads/attachment_data/file/18058 1/DFE-00035-2012.pdf

DfE. 2014a. Schools, pupils and their characteristics: January 2015. London: Department for Education. 
https://www.gov.uk/government/statistics/schools-pupils-and-their-characteristicsjanuary-2014

DfE. 2014b. School exclusion trial evaluation. Research Report, London: Department of Education.

https://www.gov.uk/government/uploads/system/uploads/attachment_data/file/33179 5/RR364_-_School_Exclusion_Trial_Final_Report.pdf

DfE. 2015a. Schools, pupils and their characteristics: January 2015. London: Department for Education.

https://www.gov.uk/government/statistics/schools-pupils-and-their-characteristicsjanuary-2015

DfE. 2015b. Children missing education: Statutory guidance for local authorities. London: Department of Education.

https://www.gov.uk/government/uploads/system/uploads/attachment_data/file/39513 8/Children_missing_education_Statutory_guidance for_local_authorities.pdf

DfE. 2015c. Revised statistics on the achievements of young people at the end of key stage 4 in the 2013 to 2014 academic year. Alternative provision and pupil referral units tables: SFR02/2015. London: Department of Education. https://www.gov.uk/government/statistics/revised-gcse-and-equivalent-results-inengland-2013-to-2014

DfE. 2016a. Permanent and fixed-period exclusions in England: 2014 to 2015. London: Department for Education.

https://www.gov.uk/government/statistics/permanent-and-fixed-period-exclusions-inengland-2014-to-2015

DfE. 2016b. The Casey Review: a review into opportunity and integration. London: Department for Communities and Local Government.

https://www.gov.uk/government/publications/the-casey-review-a-review-intoopportunity-and-integration

DfE. 2016c. Schools, pupils and their characteristics: January 2016. London: Department for Education.

https://www.gov.uk/government/statistics/schools-pupils-and-their-characteristicsjanuary-2016

DfE. 2017. Creating a Culture: How school leaders can optimise behaviour. London: Department for https://www.gov.uk/government/uploads/system/uploads/attachment_data/file/60248 7/Tom_Bennett_Independent_Review_of_Behaviour_in_Schools.pdf

Gillborn, David. 2008. Coincidence or conspiracy? Whiteness policy and the persistence of the White achievement gap, Educational Review, 60.3: 229-248.

Harris, Richard and Carl Parsons. 2014. School exclusion and English remedies: a failure to protect children, Education, Public Law and the Individual, 17.1: 20 - 28.

Huddart, Paula. 2007. Joined on rather than joined up? Primary mental health work in Scottish schools, Health Education, 107.5: 421-437.

INAURA. 2008. Community Based Inclusion. Bridgewater: Inaura. http://www.inaura.net/research/what-community-based-inclusion

INAURA. 2016. INAURA website http://www.inaura.net/about-inaura/our-story 
Mann, Tom. 2017 forthcoming. At Risk of exclusion from school yet achieving success, Education, Citizenship and Social Justice, 12.

Munn, Pamela, Gwynedd Lloyd and Mairi Ann Cullen. 2000. Alternatives to Exclusion from School. London: Paul Chapman.

OCC. 2012. "They never give up on you” School exclusions enquiry. London: Office of the Children's Commissioner.

http://www.childrenscommissioner.gov.uk/sites/default/files/publications/They\%20n ever\%20give\%20up\%20on\%20you\%20final\%20report.pdf

OCC. 2013. "Always Someone Else's Problem"- report on illegal exclusions. London: Office of the Children's Commissioner. https://www.childrenscommissioner.gov.uk/sites/default/files/publications/Always S omeone_Elses_Problem.pdf

Ofsted. 2013. Pupils missing out on education. London: Office for Standards in Education.

http://webarchive.nationalarchives.gov.uk/20141124154759/http://www.ofsted.gov.u $\mathrm{k} /$ sites/default/files/documents/surveys-and-goodpractice/p/Pupils\%20missing\%20out\%20on\%20education.pdf

Ofsted. 2014. Schools' use of exclusion. London: Office for Standards in Education. https://www.gov.uk/government/publications/schools-use-of-exclusion

Ofsted. 2016. Alternative Provision: the findings from Ofsted's three year survey of schools' use of off-site alternative provision, London: Office for Standards in Education. https://www.gov.uk/government/publications/alternative-schoolprovision-findings-of-a-three-year-survey

Parsons, Carl. 1999. Education, Exclusion and Citizenship. London: Routledge.

Parsons, Carl and Jean Hailes, 2004. Voluntary Organisations and the Contribution to Social Justice, in Schools: Learning from a Case Study, Journal of Education Policy, 19.4.: 473-496.

Parsons, Carl. 2005. School Exclusions: the will to punish. British Journal of Educational Studies, 53.2: 187- 211.

Parsons, Carl. 2009. Explaining sustained inequalities in ethnic minority school exclusion in England. Oxford Review of Education 35(2): 249-265.

Parsons, Carl. 2011a. Strategic Alternatives to Exclusion from School. Stoke on Trent: Trentham Books.

Parsons, Carl. 2011b. Collaborating to avoid exclusion, Academies Update, summer 2011: 36-37 London: Specialist Schools and Academies Trust.

Parsons, Carl. 2016. Ethnicity, gender, deprivation and low educational attainment in England - political arithmetic, ideological stances and the deficient society Education, Citizenship and Social Justice, 11 pp. 160-83.

Stead, Joan, Gwynedd Lloyd and Andrew Kendrick. 2004. Participation or practice Innovation: Tensions in inter-agency working to address disciplinary exclusions from school. Children and Society18: 42-52.

Walraven, Guido, Carl Parsons, Dolf van Veen and Chris Day. 2000. Combating Social Exclusion Through Education. Leuven: Garant. 
White, Rob and Johanna Wyn. 2008. Rethinking Youth: exploring the social dynamics of youth experience. Oxford: Oxford University Press.

Riddell, Sheila and Gillean McCluskey. 2013. 'Policy and provision for children with social, emotional and behavioural difficulties in Scotland: Intersections of gender and deprivation'. In Cole, Ted, Harry Daniels and John Visser (Eds.). The Routledge international companion to emotional and behavioural difficulties (pp. 57-67). London: Routledge.

Sloper, Patricia. 2004. Facilitators and barriers for co-ordinated multi-agency services. Child: Care, Health and Development, 30.1: 571-580.

Welsh Government, 2016. Permanent and fixed-term exclusions from schools in Wales, 2014/15. (SFR 126/2016). Cardiff: Welsh Government.

http://gov.wales/docs/statistics/2016/160928-permanent-fixed-term-exclusions-fromschools-2014-15-en.pdf

${ }^{1}$ It is notable that an appeals arrangement is still in place in the other three countries of the U.K. England has reduced the appeal to a review with limited powers to overturn an exclusion decision,

${ }^{2}$ DfE (2016a) provides data on the different types of special educational needs of excluded pupils (table 7); the largest category of special need comprises those defined as presenting with 'social, emotional and mental health' needs. This amounts to 1,300 permanent excludees and 121,000 of those with fixed period exclusion, approximately $22 \%$ of the total in each case.

${ }^{3}$ PRUs and AP may be little different. AP was once reserved for a range of provision outside the mainstream school to which a pupil might be referred, for a shorter or longer period, often comprising a mix of vocational placement and basic skills. They were often run by private providers. TBAP (say TeeBAP) is the Tri-Borough Alternative Provision, a multi-academy trust comprising sites that look like local authority PRUs, and in many cases were (http://www.tbap.org.uk).

${ }^{4}$ A Statement (of Special Educational Needs) now replaced by an Education and Health Care plan is the higher level of need and the plan is a legal document for children and young people aged up to 25 who need more support than is routinely available through special educational needs support within schools and from the LA.

${ }^{5}$ These numbers are said to have increased considerably in two years beyond the official 'registered' 26,292, according to a BBC report (BBC, 2015) based on Freedom of Information data gathered. And the Casey Report also suggests that the number of home educated young people unregistered 'is unknown and thought to be several multiples of this' (DfE, 2016b. p. 119).

${ }^{6}$ Ofsted is the Office for Standards in Education, Children's Services and Skills that inspects schools in England and reports directly to Parliament.

${ }^{7}$ An internet search for 'fair access scoring schemes' identifies a number of local authorities in England which operate through a forum where the decisions are binding on the admission authorities which might be academies or various forms of local authority governance. As local authority power declines with schools moving to academy status and LA funding is cut.

${ }^{8}$ The deprivation Pupil Premium is additional funding for FSM-Ever 6 pupils - pupils who have been eligible for free school meals, a marker for low income, at any time in the 
past six years. It is also provided for pupils who are in, or have left, local authority care. For $2016 / 17$, the grant stands at $£ 1,320$ for a primary age pupil and $£ 935$ for secondary. See https://www.gov.uk/government/publications/pupil-premium-conditions-of-grant2016-to-2017.

${ }^{9}$ The Strategic Alternatives research encountered these instances (Parsons, 2011a, p. 75) and others involved in the management of exclusions report the difficulties when a pupil was 'never on the radar'. Serious offences such as being in possession of a weapon or violence resulting in serious injury are instances given. Possession of drugs, enough to share, is another cited instance.

${ }^{10}$ In the figures for 2013/14 (DfE, 2015c, Table P1) there were nearly 9,000 15-16 yearold pupils in alternative provision including pupil referral units. Only $12.6 \%$ were entered for $5+$ GCSEs with only one tenth of these successful at the $5 \mathrm{~A}^{*}$-C grade level. 